\title{
Treatment Outcome of Traumatic Subclavian Artery Injuries
}

\author{
Parichat Tanmit (D) \\ Phati Angkasith (D) \\ Panu Teeratakulpisarn (D) \\ Chaiyut Thanapaisal \\ Narongchai Wongkonkitsin \\ Supatcha Prasertcharoensuk \\ Chaiwat Panich
}

Department of Surgery, Faculty of Medicine, Khon Kaen University, Khon Kaen, Thailand
Correspondence: Parichat Tanmit Department of Surgery, Faculty of Medicine, Khon Kaen University, 123

Mool 6 Mittraphap Road, Nai-Muang,

Muang District, Khon Kaen, 40002,

Thailand

Tel +6685000I7l4

Email pari.tanmit@gmail.com
Background: Traumatic subclavian artery injuries are associated with high morbidity and mortality. Thoracic cage and clavicle provide a well protection of the underlying subclavian vessels and nerves and also cause a very limited operation space during open surgery. The endovascular modality is less invasive and alternative to conventional open surgical reconstruction.

Purpose: The purpose of this study was to analyze the different therapeutic effects on limb salvage.

Methods: A retrospective review of patients who presented with blunt or penetrating injuries to the subclavian arteries between March 2012 and March 2021.

Results: Endovascular and open repairs were both effective for traumatic subclavian artery injury. There was no statistical difference in the limb salvage, mortality, procedure-related complication, reintervention rate and in-hospital medical complications. Intraoperative blood loss, red blood cell transfusion requirement and length of hospital stay were significantly lower in the endovascular intervention group.

Conclusion: Endovascular treatment represents an attractive alternative to the traditional surgical approach for the treatment of traumatic injuries in the subclavian.

Keywords: traumatic subclavian artery injury, blunt trauma, penetrating trauma, pseudoaneurysms, stent graft, endovascular treatment, bypass

\section{Introduction}

Traumatic subclavian artery injuries are uncommon. These injuries may cause limb ischemia and a life-threatening serious hemorrhage. ${ }^{1}$ This area contains local bony thorax structures and critical nerves. Direct surgical repair of arteries is difficult. ${ }^{2}$ The bony thorax restricts and slows exposure, most relevant in traumatic situations, and there are several nerves intimately involved with the vessels proximally which should be preserved for best outcomes. ${ }^{3}$ Conventional open approaches include a combination of supraclavicular or infraclavicular incision, median sternotomy, and thoracotomy. ${ }^{4}$ An endovascular treatment could be an effective alternative by avoiding direct dissection in the zone of injury.

\section{Materials and Methods}

Data were evaluated retrospectively for all patients who were admitted to Srinagarind Hospital of Khon Kaen University with blunt or penetrating injuries (including iatrogenic) to the subclavian arteries between March 2012 and March 2021. All the injuries have been confirmed by intraoperative exploration, 
computed tomography angiography or digital subtraction angiography. Patients who died in the emergency department were excluded from the analysis.

The purpose of this study was to compare therapeutic effects on limb salvage between the open surgical approach versus the interventional endovascular approach. Preoperative, perioperative and postoperative details were recorded. Data collected from the medical record included demographics, clinical findings such as active hemorrhage and ischemia of the limbs, mechanism of trauma, blood pressure, concomitant injuries at presentation, laboratory results and Injury Severity Scores (ISS) and treatment method. Blood loss, operation time, intraoperative blood transfusion, physiologic response, and subsequent outcomes were noted as well. Clinical evaluation and duplex ultrasound scanning or computed tomography angiography were performed to evaluate graft patency before discharge and at 1 month follow-up.

The primary outcome measure was 30-day freedom from limb amputation. Secondary outcomes were inhospital mortality, transfusion requirements, overall complication rate, device-related complication, access site complication, reintervention, acute kidney injury (AKI) with or without dialysis, sepsis, acute respiratory distress syndrome, and multiorgan dysfunction syndrome.

\section{Data Analysis}

Continuous variables were reported as mean with standard deviation. Continuous data were compared using a Student's $t$-test or Mann-Whitney $U$-test and categorical data using a Chi-squared or Fisher's exact test. Significance was assumed for $p$ values $<0.05$. Statistical analysis was completed using IBM SPSS statistics Version 26.

\section{Results}

A total of 30 patients met inclusion criteria. Nineteen patients $(63 \%)$ underwent an open surgery and endovascular repairs were performed in nine $(30 \%)$ patients. Primary amputation was performed in one case with severe arm ischemia. Arterial thrombosis, in one case with no signs of limb ischemia, was managed with observation.

The mean age was $30 \pm 17.5$ years. The patients were predominantly male $(86.7 \%)$ and injuries resulted from motor vehicle collision (50\%). (Table 1) Comparison of the general data of open and endovascular treatment is shown in Table 2.

Open surgery was performed in $19(68 \%)$ patients. There were 17 male with 2 female patients ranging in
Table I Clinical Characteristics of Study Population

\begin{tabular}{|l|l|}
\hline \multicolumn{2}{|l|}{ Demographics } \\
\hline Male, n (\%) & $26(86.7)$ \\
\hline Age (year), mean (SD) & $30 \pm 17.5$ \\
\hline Injury severity score, mean (SD) & $17.4 \pm 8.5$ \\
\hline Mechanism of injury, n (\%) & \\
-Motor vehicle collision & $15(50)$ \\
-Motorcycle crash & $1(3.3)$ \\
-Catheter related complication & $4(13.3)$ \\
-Intraoperative iatrogenic injury & $3(10)$ \\
-Stab & $4(13.3)$ \\
-Gunshot & $2(6.7)$ \\
-Fall from height & $\mathrm{I}(3.3)$ \\
\hline
\end{tabular}

age from 14 to 60 years (mean $35.95 \pm 14.20$ years). Motor vehicle collisions were the most common causes of injury that accounted for $47 \%$ of the cases. Injury severity score in this group of patients ranged from 8 to 34 (mean $16.47 \pm 8.56$ ). The most common associated lesions were subclavian vein injuries (Table 3). Most patients initially present with ischemic symptoms (pain, pallor, pulselessness, paresthesia, paralysis, and poikilothermia). Eight patients (42\%) were seen with completed arterial transection and six patients (32\%) were seen with arterial contusion and thrombosis. The infraclavicular approach was employed in 15 (79\%) patients. A supraclavicular approach, median sternotomy, standard posterolateral thoracotomy, and trapdoor incision were used in one patient per technique. Arterial reconstruction with synthetic PTFE grafts was performed in 10 cases $(53 \%)$ and reverse saphenous vein graft was used in one case $(5 \%)$. Primary anastomosis of the injured artery was performed in 2 patients (11\%). Two cases underwent lateral arteriorrhaphy and arterial ligation were performed in three cases (16\%). (Table 5) No temporary vascular shunt was applied. The initial amputation was done in one case with a nonviable limb. Two patients required arm amputation because of severe limb ischemia from bypass graft thrombosis.

Nine patients (32\%) underwent endovascular intervention. The mean age was 41.44 years (range 20-86) among $7(77 \%)$ males and $2(22 \%)$ females. The two most common mechanisms of injuries were motor vehicle collisions (44\%) and catheter-related complications (44\%) (Table 2). The most common concomitant injury was subclavian vein $(56 \%)$, followed by clavicle fracture (44\%). Injury severity 
Table 2 Comparison of Preoperative Demographic Data and Clinical Characteristics

\begin{tabular}{|c|c|c|c|}
\hline Variable & Open Repair $(n=19)$ & Endovascular Repair $(n=9)$ & p-value \\
\hline Age (year), mean (SD) & $35.95(14.20)$ & $41.44(23.72)$ & 0.096 \\
\hline Gender: Male, n (\%) & $17(89.47)$ & $7(77.78)$ & 0.574 \\
\hline $\begin{array}{l}\text { Mechanism of injury, } \mathrm{n}(\%) \\
\text {-Motor vehicle collision } \\
\text {-Motorcycle crash } \\
\text {-Auto vs Pedestrian } \\
\text {-Catheter related complication } \\
\text {-Intraoperative iatrogenic injury } \\
\text {-Stab } \\
\text {-Gunshot } \\
\text {-Fall from height }\end{array}$ & $\begin{array}{l}9(47.37) \\
1(5.26) \\
0(0.00) \\
0(0.00) \\
3(15.79) \\
3(15.79) \\
2(10.53) \\
1(5.26)\end{array}$ & $\begin{array}{l}4(44.44) \\
0(0.00) \\
0(0.00) \\
4(44.44) \\
0(0.00) \\
I(11.11) \\
0(0.00) \\
0(0.00)\end{array}$ & 0.06 \\
\hline $\begin{array}{l}\text { Shock grade, n (\%) } \\
\begin{array}{l}1 \\
2 \\
3 \\
4\end{array}\end{array}$ & $\begin{array}{l}\text { I3 (68.42) } \\
\text { I }(5.26) \\
2(10.53) \\
3(15.79)\end{array}$ & $\begin{array}{l}7(77.78) \\
0(0.00) \\
I(11.11) \\
I(11.11)\end{array}$ & 0.81 \\
\hline $\begin{array}{l}\text { Clinical } \\
\text { Pulsatile bleeding, n (\%) } \\
\text { Expansile hematoma, n (\%) } \\
\text { Audible thrill, n (\%) } \\
\text { Ischemic symptoms, n (\%) } \\
\text { History of massive external bleeding, n (\%) } \\
\text { Peripheral neurological deficit, n (\%) } \\
\text { Proximal wound to vessel, n (\%) } \\
\text { Diminish distal pulse, n (\%) }\end{array}$ & $\begin{array}{l}6(31.58) \\
5(26.32) \\
\text { I }(5.26) \\
\text { II }(57.89) \\
\text { I }(5.26) \\
3(15.79) \\
0(0.00) \\
0(0.00)\end{array}$ & $\begin{array}{l}3(33.33) \\
\text { I }(\text { II.II }) \\
\text { I }(\text { II.II }) \\
3(33.33) \\
\text { I (II.II) } \\
2(22.22) \\
\text { I (II.II) } \\
\text { I (II.II) }\end{array}$ & $\begin{array}{l}0.93 \\
0.36 \\
0.58 \\
0.23 \\
0.58 \\
0.68 \\
0.14 \\
0.14\end{array}$ \\
\hline
\end{tabular}

score in this group of patients ranged from 8 to 36 (mean $17.78 \pm 8.96)$ (Table 3). Pulsatile hemorrhage (33\%) and limb ischemia in the affected extremities (33\%) were common clinical presentations. Arterial wall laceration occurred in $56 \%$ of cases. The procedures were performed in the operative theater with full endovascular capability and suitable for multidisciplinary management of trauma patients. The brachial artery or femoral artery was accessed. A combined brachial and femoral artery approach was used to create a through-and-through wire and repair the transected artery. Stent grafts were used in eight patients (89\%). Technical success was obtained in all cases without procedure-related complications. One patient received transcatheter arterial embolization of pseudoaneurysm and re-embolization was required due to expanding hematoma. We report two cases of early postoperative mortality secondary to severe sepsis and Metformin-associated lactic acidosis.

Clinical characteristics and demographics were compared between these two groups. There were no differences in age, gender, mechanism of trauma, vital signs on arrival, injury severity score and trauma injury severity score between the two study groups. Patients with endovascular intervention had a higher incidence of clavicle fracture $(p=0.03)$ and a higher preoperative creatinine $(p=0.01)$ (Table 4). Intraoperative blood loss, red blood cell transfusion requirement and length of hospital stay were significantly lower in the endovascular intervention group ( $p=0.03,0.01$ and 0.04 ) (Table 6). There was no statistical difference in the limb salvage, mortality, procedure-related complication, reintervention rate and inhospital medical complications (Table 7).

\section{Discussion}

Traumatic subclavian artery injuries are reported in less than $5 \%$ of all traumatic arterial injury. ${ }^{5}$ Injuries are associated with high morbidity and mortality. Overall mortality of patients with axillo-subclavian artery injury who receiving operation range from $5 \%$ to $30 \%{ }^{2,6,7}$ 
Table 3 Associated Injuries of Patients

\begin{tabular}{|c|c|c|c|}
\hline Variable & Open Repair $(n=19)$ & Endovascular Repair ( $n=9)$ & p-value \\
\hline Abbreviated Injury Scale, mean(SD) & & & \\
\hline Head/neck & $1.89(1.24)$ & $1.67(1.66)$ & 0.69 \\
\hline Face & $0.11(0.32)$ & $0.00(0.00)$ & 0.33 \\
\hline Thorax & $1.63(1.80)$ & $3.00(1.23)$ & 0.05 \\
\hline Abdomen & $0.26(0.8 I)$ & $0.00(0.00)$ & 0.34 \\
\hline Extremity & $1.79(1.32)$ & I.II (I.05) & 0.19 \\
\hline External & $0.21(0.42)$ & $0.22(0.44)$ & 0.95 \\
\hline Injury severity score, mean (SD) & $16.47(8.56)$ & $17.78(8.96)$ & 0.71 \\
\hline Subclavian vein injury, $\mathrm{n}(\%)$ & $14(73.68)$ & $5(55.56)$ & 0.34 \\
\hline Brachial plexus, n (\%) & $6(31.58)$ & $3(33.33)$ & 0.93 \\
\hline Clavicle fracture, $\mathrm{n}(\%)$ & I (5.26) & $4(44.44)$ & 0.03 \\
\hline Scapular fracture, $n$ (\%) & $3(15.79)$ & $3(33.33)$ & 0.29 \\
\hline Rib fracture, $n(\%)$ & $4(21.05)$ & $2(22.22)$ & 0.94 \\
\hline Pneumohemothorax, n (\%) & I (5.26) & $2(22.22)$ & 0.18 \\
\hline Spine fracture, n (\%) & I (5.26) & I (II.II) & 0.76 \\
\hline Liver injury, n (\%) & I (5.26) & $0(0.00)$ & 0.48 \\
\hline Long bone fracture, $\mathrm{n}(\%)$ & $7(36.84)$ & $0(0.00)$ & 0.06 \\
\hline
\end{tabular}

Table 4 Preoperative Laboratory Evaluation of Patients

\begin{tabular}{|l|l|l|l|}
\hline Variable & Open Repair (n=19) & Endovascular Repair (n=9) & p-value \\
\hline Creatinine (mg/dL) & $0.85(0.3 \mathrm{I})$ & $2.17(2.48)$ & 0.01 \\
Hemoglobin (g/dL), mean (SD) & $10.62(2.47)$ & $11.00(2.23)$ & 0.88 \\
Platelet $(/ \mu \mathrm{L})$, mean (SD) & $173,666(75,249)$ & $228,666(100,601)$ & 0.39 \\
Prothrombin time (seconds), mean (SD) & $12.94(2.2 \mathrm{I})$ & $12.77(1.6 \mathrm{I})$ & 0.25 \\
Activated partial thromboplastin Time (seconds), mean (SD) & $39.03(24.93)$ & $33.28(6.85)$ & 0.09 \\
International Normalized Ratio, mean (SD) & $1.18(0.19)$ & $1.14(0.15)$ & 0.45 \\
Blood pH level, mean (SD) & $7.47(0.05)$ & $7.37(0.07)$ & 0.46 \\
\hline
\end{tabular}

Table 5 Open Operative Repair

\begin{tabular}{|l|l|}
\hline Incision (Open Surgery), $\mathbf{n}(\%)$ & \\
Supraclavicular & $\mathrm{I}(5.26)$ \\
Infraclavicular & $\mathrm{I} 5(78.95)$ \\
Sternotomy & $\mathrm{I}(5.26)$ \\
Posterolateral thoracotomy & $\mathrm{I}(5.26)$ \\
Trapdoor & $\mathrm{I}(5.26)$ \\
\hline Type of Repair, $\mathbf{n}$ (\%) & \\
Lateral arteriorrhaphy & $2(10.53)$ \\
Resection and primary anastomosis & $2(10.53)$ \\
PTFE graft & $10(52.63)$ \\
Reverse saphenous vein graft & $\mathrm{I}(5.26)$ \\
Ligation & $3(15.79)$ \\
Primary amputation & $\mathrm{I}(5.26)$ \\
\hline
\end{tabular}

The majority of subclavian vessel injuries in the civilian population result from penetrating trauma. ${ }^{8}$ The mechanism of injury in our study is most commonly blunt because of motor vehicle collisions. High-speed motor vehicle accidents can be devastating and produce significantly more tissue damage.

The immediate management consists of assessing a patient's condition rapidly and accurately, then resuscitating and stabilizing the patient. The diagnoses may be suspected clinically, including active hemorrhage, hematoma and ischemia of the limb. However, the collateral circulation of the upper extremities is so extensive that patients may even have palpable distal pulses after the vessels are 
Table 6 Comparison of Operative Data

\begin{tabular}{|c|c|c|c|}
\hline Operative Data & Open Repair $(n=19)$ & Endovascular Repair $(n=9)$ & p-value \\
\hline \multicolumn{4}{|l|}{ Vessel injury pattern, n (\%) } \\
\hline -Laceration & $3(15.79)$ & $5(55.56)$ & 0.90 \\
\hline -Complete Transection & $8(42.11)$ & I (II.II) & \\
\hline -Incomplete transection & $6(31.58)$ & $0(0.00)$ & \\
\hline -Contusion and thrombosis & I (5.26) & $2(22.22)$ & \\
\hline -False aneurysm & I (5.26) & I (II.II) & \\
\hline Fasciotomy, n (\%) & $5(26.32)$ & $0(0.00)$ & 0.14 \\
\hline Time to operation (hour), mean (SD) & $23.38(26.81)$ & $50.25(60.10)$ & 0.11 \\
\hline Operation time (minute), mean (SD) & |86.4| (74.68) & I $40.25(89.60)$ & 0.44 \\
\hline Estimated blood loss (mL), mean (SD) & $23 \mid 4.38(3575.11)$ & $206.88(227.01)$ & 0.03 \\
\hline Intraoperative Packed red cells (unit), mean (SD) & $4.31(5.64)$ & $0.63(1.19)$ & 0.01 \\
\hline
\end{tabular}

Table 7 Comparison of Post-Operative Data

\begin{tabular}{|c|c|c|c|}
\hline Post-Operative Data & Open Repair $(n=19)$ & Endovascular Repair $(n=9)$ & p-value \\
\hline Vasopressor requirement (case) & 2 & 2 & 0.42 \\
\hline Reoperation due to bleeding (case) & 0 & I & 0.32 \\
\hline Reoperation due to thrombosis (case) & 2 & 0 & 0.31 \\
\hline Surgical site infections (case) & 5 & 0 & 0.14 \\
\hline \multicolumn{4}{|l|}{ In-hospital complications } \\
\hline Acute renal failure (case) & I & 0 & 0.48 \\
\hline Mechanical Ventilation require more than 48 hours (case) & 6 & 2 & 0.61 \\
\hline Limb ischemia (case) & 2 & 0 & 0.31 \\
\hline Limb compartment syndrome (case) & 0 & 0 & - \\
\hline Pneumonia (case) & I & 0 & 0.48 \\
\hline Acute respiratory distress syndrome (case) & I & 0 & 0.48 \\
\hline Sepsis (case) & 8 & 2 & 0.31 \\
\hline ICU stay (day), mean (SD) & $3.06(3.68)$ & $3.89(4.42)$ & 0.70 \\
\hline Hospital stay(day), mean (SD) & $16.94(12.77)$ & $6.13(4.26)$ & 0.04 \\
\hline Ventilator day(day), mean (SD) & $1.94(2.11)$ & I $(1.80)$ & 0.63 \\
\hline Inhospital mortality (case) & I & 2 & 0.23 \\
\hline 30 day mortality (case) & 1 & 2 & 0.23 \\
\hline Time to death (day) & $1.5(2.12)$ & $3.33(2.89)$ & 0.39 \\
\hline Need re intervention (case) & 0 & 1 & 0.30 \\
\hline Limb amputation (total) (case) & 3 & 0 & 0.53 \\
\hline Post revascularization amputation (case) & 2 & 0 & 0.31 \\
\hline
\end{tabular}

completely transected. ${ }^{1}$ The computed tomography angiography (CTA) is a reliable noninvasive modality for diagnosis and helpful in planning the operative approach. Duplex ultrasound imaging can provide crucial information for unstable critically ill patients and allows a careful selection of patients who require undergoing in-depth imaging methods or surgical therapy, thus contributing to a significant reduction of contrast medium and exposure to ionizing radiation. ${ }^{9}$ Intraoperative angiography allows for the direct simultaneous assessment of blood perfusion and further surgical intervention.

Management of vascular injuries, especially when they occur in combination with bony fractures, soft tissue loss, nerve damage and contamination is an extremely challenging situation. Our data are in agreement with previous reports showing that blunt trauma is frequently associated with major musculoskeletal and brachial plexus injury. ${ }^{10}$ Traumatic subclavian artery is difficult to expose due to 
hematoma formation and anatomical complexity. Thoracic cage and clavicle provide a well protection of the underlying nerves and blood vessels and also cause a very limited operation space during open surgery. ${ }^{11}$

The principles of open vascular repair include obtaining adequate exposure, proximal and distal control, restoration of perfusion, prevention of ischemia reperfusion and compartment syndrome. ${ }^{12}$ The endovascular modality is less invasive and alternative to conventional open surgical reconstruction. A review of the literature using endovascular repair of traumatic injuries in the subclavian arteries shows a high degree of technical success and excellent patency rates. ${ }^{13}$

Interventional stent implantation and transcatheter embolization offer an effective, efficient and safe alternative to conventional surgical management. ${ }^{14,15}$

In this study, endovascular and open repairs were both effective for limb salvage. No statistically significant association was found between surgical approaches and 30-day limb amputation, in-hospital mortality, overall complication rate, device-related complication, access site complication, reintervention, acute kidney injury (AKI) with or without dialysis, sepsis, acute respiratory distress syndrome, and multiorgan dysfunction syndrome. Technical success rate of endovascular treatment is good. However, endovascular management is less invasive, less blood loss, less red blood cell transfusion requirement and shorter length of hospital stay.

The potential benefits of endovascular versus open repair consist of shorter operative duration and less intravenous fluid requirement.

The early complications consisted of graft thrombosis after open reconstruction and endoleak after treatment of a pseudoaneurysm. No severe access-related complication was found. Two cases required arm amputation because of severe limb ischemia from bypass graft thrombosis.

Inadvertent arterial puncture can lead to devastating complications. We retrospectively identified 6 cases of subclavian artery injury following central venous catheterization. Two of them were unrecognized for the injury and all had severe complications resulting in hemorrhagic shock and death. Three patients were treated using an endovascular approach after pulsatile flow was observed from the catheter. One case failed attempted right jugular vein access and computed tomography angiography demonstrated subclavian artery false aneurysm. In all four cases, the covered stent placement was technically successful without procedure-related complications.
Endovascular management of iatrogenic injury to the subclavian artery is a safe and effective alternative to open surgery. ${ }^{16,17}$

\section{Limitations}

There are some limitations in our study. Traumatic subclavian artery is a rare vascular injury. There have been a small number of cases. The data were collected retrospectively and thus limited by the usual limitations of retrospectively collected data. Furthermore, we cannot exclude selection bias for operative procedure.

\section{Conclusion}

Endovascular and open repairs were both effective for traumatic subclavian artery injury. A cover stent may be useful for life-threatening hemorrhage and restore blood flow to an ischemic limb and allow nonoperative management of the subclavian artery. Endovascular therapy appears to be a feasible treatment option with intraoperative blood loss, red blood cell transfusion requirement and length of hospital stay lower than those seen in open surgery.

\section{Ethics Declarations}

This retrospective study was approved by the Center for Ethics in Human Research of Khon Kaen University (KKUEC), and the committee's reference number is HE641010. This study represents no more than minimal risk to subjects and will not adversely affect their rights and welfare. All patient identifiers will be removed once the data from the patient medical records are collected. All elements of informed consent are being asked to be waived for this study. The study was conducted in compliance with the Declaration of Helsinki.

\section{Acknowledgments}

The authors gratefully acknowledge the Srinagarind hospital surgeons team and the nursing team for their contributions to the work presented in this paper.

\section{Funding}

There is no funding to report.

\section{Disclosure}

The authors declare that they have no conflicts of interest in this work. 


\section{References}

1. McCready RA, Procter CD, Hyde GL. Subclavian-axillary vascular trauma. J Vasc Surg. 1986;3(1):24-31. doi:10.1016/0741-5214(86) 90065-0

2. Demetriades D, Asensio JA. Subclavian and axillary vascular injuries. Surg Clin North Am. 2001;81(6):1357-1373. doi:10.1016/S00396109(01)80012-8

3. Committee American College of Surgeon. Advanced Surgical Skills for Exposure in Trauma. Chicago: American College of Surgeon; 2010.

4. Abouljoud MS, Obeid FN, Horst HM, Sorensen VJ, Fath JJ, Chung SK. Arterial injuries of the thoracic outlet: a ten-year experience. Am Surg. 1993;59(9):590-595.

5. Perry MO, Thal ER, Shires GT. Management of arterial injuries. Ann Surg. 1971;173(3):403-408. doi:10.1097/00000658-197103000-00011

6. Schaff HV, Brawley RK. Operative management of penetrating vascular injuries of the thoracic outlet. $J$ Trauma. 1977;17(12):981. doi:10.1097/00005373-197712000-00022

7. Degiannis E, Levy RD, Potokar T, Saadia R. Penetrating injuries of the axillary artery. ANZ J Surg. 1995;65(5):327-330. doi:10.1111/j.14452197.1995.tb00647.x

8. Sciarretta JD, Pepe A, Dickson L. Penetrating subclavian vessel injury: diagnosis and treatment. Emerg Med Open Access. 2013;3:143.

9. Corvino A, Catalano O, de Magistris G, et al. Usefulness of Doppler techniques in the diagnosis of peripheral iatrogenic pseudoaneurysms secondary to minimally invasive interventional and surgical procedures: imaging findings and diagnostic performance study. J Ultrasound. 2020;23(4):563-573. doi:10.1007/s40477-020-00475-6
10. Klocker J, Falkensammer J, Pellegrini L, Biebl M, Tauscher T, Fraedrich G. Repair of arterial injury after blunt trauma in the upper extremity - immediate and long-term outcome. Eur J Vasc Endovasc Surg. 2010;39(2):160-164. doi:10.1016/j.ejvs.2009.11.019

11. Tadayon N, Yavari N, Zarrintan S, Hosseini SM, Kalantar-Motamedi SMR. Management of traumatic subclavian artery injuries in a high-volume vascular surgery center in Iran. $J$ Cardiovasc Thorac Res. 2020;12(2):145-149. doi:10.34172/jcvtr.2020.24

12. Martin MJ, Perez-Alonso AJ, Asensio JA. Vascular complications and special problems in vascular trauma. Eur J Trauma Emerg Surg. 2013;39(6):569-589. doi:10.1007/s00068-013-0336-9

13. Jacks R, Degiannis E. Endovascular therapy and controversies in the management of vascular trauma. Scand J Surg. 2014;103 (2):149-155. doi:10.1177/1457496914532248

14. Tian X, Liu JL, Jia W, et al. Comparison of traditional vascular reconstruction with covered stent in the treatment of subclavian artery injury. Chin J Traumatol. 2020;23(1):25-28. doi:10.1016/j. cjtee.2019.11.007

15. Corvino F, Giurazza F, Cangiano G, et al. Safety and effectiveness of transcatheter embolization in the treatment of internal mammary artery injuries. Radiol Med. 2018;123(5):369-377. doi:10.1007/ s11547-017-0844-5

16. Leonardou P, Pappas P. Urgent endovascular treatment of iatrogenic subclavian artery rupture: report of three cases. Ulus Travma Acil Cerrahi Derg. 2012;18(6):527-530. doi:10.5505/tjtes.2012.50374

17. Chemelli AP, Wiedermann F, Klocker J, et al. Endovascular management of inadvertent subclavian artery catheterization during subclavian vein cannulation. J Vasc Interv Radiol. 2010;21(4):470-476. doi:10.1016/j.jvir.2009.12.392
Vascular Health and Risk Management

\section{Publish your work in this journal}

Vascular Health and Risk Management is an international, peerreviewed journal of therapeutics and risk management, focusing on concise rapid reporting of clinical studies on the processes involved in the maintenance of vascular health; the monitoring, prevention and treatment of vascular disease and its sequelae; and the involvement

\section{Dovepress}

of metabolic disorders, particularly diabetes. This journal is indexed on PubMed Central and MedLine. The manuscript management system is completely online and includes a very quick and fair peerreview system, which is all easy to use. Visit http://www.dovepress. com/testimonials.php to read real quotes from published authors. 